\author{
Marquette University \\ e-Publications@Marquette
}

$12-2014$

\title{
Disinfection Byproduct Formation Resulting from Settled, Filtered, and Finished Water Treated by Titanium Dioxide Photocatalysis
}

Brooke K. Mayer

Marquette University, Brooke.Mayer@marquette.edu

Erin Daugherty

Arizona State University at the Tempe Campus

Morteza Abbaszadegan

Arizona State University at the Tempe Campus

Follow this and additional works at: https://epublications.marquette.edu/civengin_fac

Part of the Civil and Environmental Engineering Commons

\section{Recommended Citation}

Mayer, Brooke K.; Daugherty, Erin; and Abbaszadegan, Morteza, "Disinfection Byproduct Formation Resulting from Settled, Filtered, and Finished Water Treated by Titanium Dioxide Photocatalysis" (2014).

Civil and Environmental Engineering Faculty Research and Publications. 36.

https://epublications.marquette.edu/civengin_fac/36 
Marquette University

e-Publications@Marquette

\section{Civil, Construction and Environmental Engineering Faculty Research and Publications/College of Engineering}

This paper is NOT THE PUBLISHED VERSION; but the author's final, peer-reviewed manuscript. The published version may be accessed by following the link in the citation below.

Chemosphere, Vol. 117 (December 2014): 72-78. DOI. This article is C Elsevier and permission has been granted for this version to appear in e-Publications@Marquette. Elsevier does not grant permission for this article to be further copied/distributed or hosted elsewhere without the express permission from Elsevier.

\section{Disinfection Byproduct Formation Resulting from Settled, Filtered, And Finished Water Treated by Titanium Dioxide Photocatalysis}

Brooke K. Mayer

Marquette University, Milwaukee, WI

Erin Daugherty

Arizona State University, Tempe, AZ

Morteza Abbaszadegan

Arizona State University, Tempe, AZ

\section{Abstract}

This study evaluated strategies targeting disinfection byproduct (DBP) mitigation using $\mathrm{TiO}_{2}$ photocatalysis with varying influent water quality. A Purifics Photo-CAT Lab reactor was used to assess total trihalomethane (TTHM) 
and haloacetic acid (HAA) formation as a function of photocatalytic treatment using water from a conventional coagulation/flocculation/sedimentation process, granular activated carbon filtration, and a DBP hot spot in the water distribution system. Regardless of influent water quality, photocatalysis reduced DBP precursors; however, low-energy limited photocatalysis $\left(<5 \mathrm{~kW} \mathrm{~h} \mathrm{~m}^{-3}\right)$, exacerbated the production of TTHMs and HAA5s beyond initial levels. Accordingly, limited photocatalysis is not a suitable option when TTHMs and HAA5s are a concern, regardless of the level of pretreatment. Limited photocatalysis yields incomplete oxidation, wherein larger, more aromatic, humic organic compounds are broken into smaller molecular weight, less aromatic, and less humic moieties, which have considerable potential to produce DBPs. More complete mineralization of DBP precursors is obtained using extended photocatalysis $\left(80-160 \mathrm{~kW} \mathrm{~h} \mathrm{~m}^{-3}\right)$, which substantially decreases DBP precursors as well as TTHM and HAA5 concentrations. In order to balance DBP mitigation, energy, and chemical usage, targeted use of $\mathrm{TiO}_{2}$ photocatalysis is necessary in a water treatment train (e.g., extended photocatalysis at a distribution system hot spot, where the volumetrically high energy requirements may be justifiable).

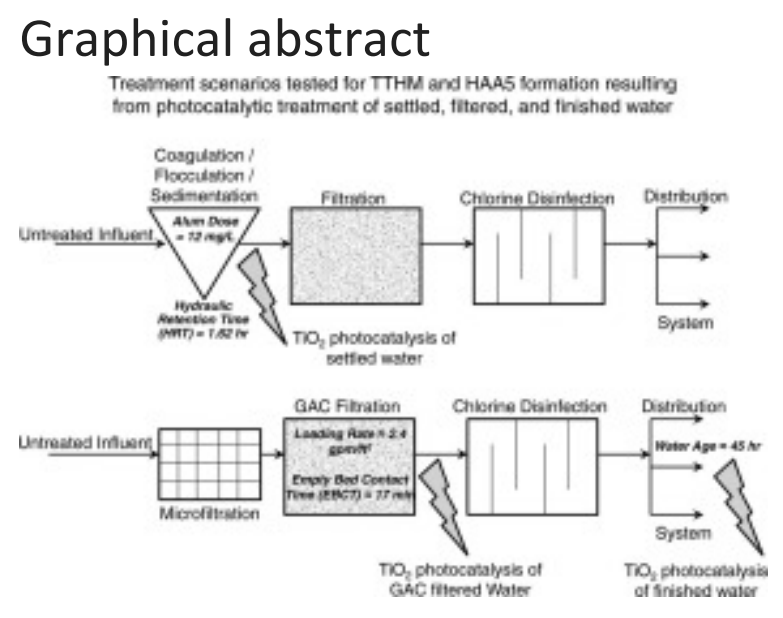

\section{Keywords}

Disinfection byproduct, Advanced oxidation, Titanium dioxide photocatalysis, Trihalomethane, Haloacetic acid, Organic matter characterization

\section{Introduction}

The formation of potentially harmful disinfection byproducts (DBPs) occurs when oxidizing disinfectants react with natural organic matter (NOM), and is a significant concern in water treatment (Richardson, 2003). Increasingly stringent DBP requirements (USEPA, 2006) have led to the reevaluation and investigation of strategies to mitigate DBPs and maintain system-wide regulatory compliance. Chlorinated DBPs, of which total trihalomethanes (TTHMs) and haloacetic acids (HAA5s) are the most prevalent (Krasner et al., 2006), may be avoided by employing alternative disinfectants. However, these may also form DBPs and/or be ineffective against certain pathogenic microorganisms (Richardson, 2003, USEPA, 2006). Alternate DBP mitigation strategies target removal of precursor NOM, with best available processes identified as enhanced coagulation or softening, granular activated carbon (GAC), or membrane filtration (USEPA, 2006, Liu et al., 2008). Innovative technologies such as advanced oxidation processes (AOPs) are also being investigated, and are increasingly attractive as they have the potential to mineralize NOM rather than merely capturing and transferring it to another phase; furthermore, they may not require large chemical doses or $\mathrm{pH}$ adjustment and no sludge is formed (Liu et al., 2008, Thiruvenkatachari et al., 2008).

AOPs such as $\mathrm{TiO}_{2}$ photocatalysis rely on the production of nonspecific radical species, which are capable of oxidizing a wide array of contaminants (Gerrity et al., 2009). During photocatalysis, UV light $(\lambda<387 \mathrm{~nm})$ is used 
to irradiate a semiconductor photocatalyst in order to produce readily reactive radical species such as. $\mathrm{OH}$. The heterogeneous nature of the $\mathrm{TiO}_{2}$ also provides a surface for physical adsorption (Huang et al., 2008, Liu et al., 2008, Tercero Espinoza and Frimmel, 2009), thereby yielding a multi-pronged treatment approach. The efficacy of photocatalysis for DBP mitigation depends on the influent concentration and composition of NOM, which varies dramatically as initially untreated water undergoes a series of physicochemical treatment operations.

There is general agreement that the primary DBP precursor NOM fractions are hydrophobic and within the apparent molecular weight range of 1-10 kDa (Chow et al., 2005). However, in many cases, hydrophilic and lower molecular weight fractions have contributed significantly to DBP formation (Hwang et al., 2001, Liu et al., 2008). Photocatalytic treatment tends to shift NOM composition toward these moieties, with Liu et al. (2008) reporting a shift in the hydrophilic fraction from $15 \%$ to $90 \%$ following photocatalytic treatment. Accordingly, DBPs are still formed following photocatalysis, and can even be exacerbated beyond initial levels (Liu et al., 2008, Gerrity et al., 2009). Gerrity et al. (2009) observed an increase in TTHM formation of up to 75\% using limited photocatalysis $\left(\leqslant 5 \mathrm{~kW} \mathrm{~h} \mathrm{~m}^{-3}\right)$ to treat raw water. When higher energy levels were used, DBP formation decreased substantially, e.g., 95\% reduction in TTHMs (Gerrity et al., 2009). Unfortunately, this improved performance was highly energy intensive, likely rendering it economically prohibitive for high flow water treatment applications.

Optimization of sequential treatment processes using limited energy $\mathrm{TiO}_{2}$ photocatalysis following conventional treatment operations such as adsorption and filtration may target the removal/destruction of both hydrophobic and hydrophilic fractions to simultaneously minimize DBP formation and system inputs such as chemicals and energy (Hua and Reckhow, 2007). This study is the first evaluation of strategies targeting mitigation of TTHMs and $\mathrm{HAA} 5 \mathrm{~s}$ using $\mathrm{TiO}_{2}$ photocatalysis to treat water from a conventional coagulation/flocculation/sedimentation process, GAC filter, and a hot spot in the water distribution system.

\section{Materials and methods}

Central Arizona water was collected from different locations in the drinking water treatment train: following sedimentation (SW), following GAC filtration (GAC), and from a hot spot in the distribution system (DS) characterized by elevated DBP concentrations. The water samples were stored at $4{ }^{\circ} \mathrm{C}$ for up to $24 \mathrm{~h}$ before being treated using photocatalysis.

\subsection{Pilot-scale photocatalysis}

Photocatalysis was performed using the Purifics (London, ON) Photo-CAT Lab reactor, as described by Gerrity et al. (2009). The reactor was operated in batch configuration at a process flow rate of $25 \mathrm{~L} \mathrm{~min}^{-1}$ using $1 \mathrm{~g} \mathrm{~L}^{-1}$ suspended reagent-grade Degussa P25 $\mathrm{TiO}_{2}$ (Dusseldorf, Germany), based on previous studies (Liu et al., 2008, Gerrity et al., 2009). The average intensity of the UV bulbs was approximately $7.0 \mathrm{~mW} \mathrm{~cm}^{-2}$, as estimated using biodosimetry (Gerrity et al., 2008). Energy consumption (UV lamps only, not accounting for pumps, controls, etc.) was kept constant for each respective sample by adjusting reaction time to account for changes in volume due to sampling.

Five samples representing increasing levels of photocatalytic treatment were collected for each water source: an initial control sample, dark adsorption, and three photocatalytic treatment levels: limited $\left(5 \mathrm{~kW} \mathrm{~h} \mathrm{~m}^{-3}\right)$, medium $\left(80 \mathrm{~kW} \mathrm{~h} \mathrm{~m}^{-3}\right)$, and extended photocatalysis $\left(160 \mathrm{~kW} \mathrm{~h} \mathrm{~m}^{-3}\right)$, representing partial, incomplete, and nearcomplete oxidation, respectively. The dark adsorption samples (no UV) provided a measure of physical removal due to $\mathrm{TiO}_{2}$ adsorption and filtration through the PhotoCAT's ceramic membrane. 


\subsection{Analytical measurements}

A Mettler (Columbus, $\mathrm{OH}$ ) pH meter was used to measure $\mathrm{pH}$, while turbidity was measured using a Hach (Loveland, CO) model 2100P turbidimeter. Control samples were filtered using $0.45 \mu \mathrm{m}$ Pall (Port Washington, NY) Acrodisc ${ }^{\circledR}$ GHP membrane filters to remove particulate matter prior to other analyses.

\subsubsection{DBP precursors}

Ultraviolet absorbance at a wavelength of $254 \mathrm{~nm}\left(\mathrm{UV}_{254}\right)$ was measured using a Hach DR 5000 spectrophotometer. Samples were acidified with $1 \mathrm{M} \mathrm{HCl}$ prior to analysis of dissolved organic carbon (DOC) using a Shimadzu (Kyoto, Japan) 5050A Total Organic Carbon Analyzer. Specific ultraviolet absorbance (SUVA) was calculated by normalizing $U_{254}$ with respect to DOC. Bromide was measured using a Dionex (Sunnyvale, CA) DX-120 ion chromatograph.

\subsubsection{DBP formation}

Samples were chlorinated in accordance with a modified simulated distribution system test (SDS-THM, APHA, 2005) in which chlorine was added to each sample to target a residual of $1 \mathrm{mg} \mathrm{L}^{-1}$ after $24 \mathrm{~h}$ at $28^{\circ} \mathrm{C}$. Preliminary assessments of all samples were performed to determine the 24-h chlorine demand using a chlorine dosing curve. Free chlorine was analyzed using a Hach D4/4000U spectrophotometer and DPD free chlorine reagent powder pillows.

Samples were collected $24 \mathrm{~h}$ post-chlorination for DBP analysis. TTHMs are the sum of four species (chloroform, bromodichloromethane, dibromochloromethane, and bromoform), which were analyzed in accordance with USEPA Method 524.2 using a 4660 concentrator with an Agilent Technologies (Santa Clara, CA) HP 6890 Plus GC-MS system. Five HAAs (HAA5s: chloroacetic acid, dichloroacetic acid, trichloroacetic acid, bromoacetic acid, and dibromoacetic acid) were analyzed in accordance with USEPA Method 552 using an Applied Biosystems (Carlsbad, CA) Triple Quadrupole MS (ABI Qtrap) system.

\subsubsection{Organic matter characterization}

The nonfractionated NOM was characterized using molecular weight distributions and UV absorption spectra. Apparent molecular weight (AMW) was determined by high-performance size exclusion chromatography (HPSEC) with online DOC detection, in accordance with Her et al. (2002). As described by Gerrity et al. (2009), samples were analyzed with a Waters (Milford, MA) Alliance 2695 Separations Module and a HW-50S Toyopearl (Stuttgart, Germany) polymeric column. The high-performance liquid chromatograph was connected to a Sievers (GE Analytical Instruments, Boulder, CO) 800 Portable TOC Analyzer.

Fluorescence spectroscopy electron emission matrices (EEMs) were performed using a PerkinElmer LS-50B luminescence spectrometer with a xenon excitation source. Excitation $(\lambda=200-400 \mathrm{~nm})$ and emission $(\lambda=290-$ $550 \mathrm{~nm}$ ) slits were set to a 5-nm band pass. No adjustments were made for DOC or ionic strength. Background fluorescence determined using nanopure water was subtracted from results, with a minimum allowable reading of zero. Fluorescence regional integration (FRI) was used to assess qualitative shifts in NOM composition, as described by Chen et al. (2003). Briefly, the EEMs were delineated into characteristic excitation-emission regions: Region I - Aromatic protein I, Region II - Aromatic protein II, Region III - Fulvic acid-like, Region IV Soluble microbial byproduct-like, and Region V-Humic acid-like.

\section{Results and discussion}

In general, $\mathrm{pH}$ was unaffected by photocatalytic treatment, and ranged from 7.5 to 8.5 for all samples. Initial turbidity levels in the SW, GAC, and DS were $0.90,0.39$, and 0.09 NTU, respectively. Following filtration in the Photo-CAT system, the turbidity of all samples was $<0.25$ NTU. 


\subsection{DBP precursors}

The removal profiles of the DBP precursors DOC and $U_{254}$ are shown in Fig. 1. As illustrated, $U_{254}$ exhibited greater removal than DOC, with maximum removals of $85-100 \%$ and $75-87 \%$, respectively, at $160 \mathrm{~kW} \mathrm{~h} \mathrm{~m}^{-3}$. Moreover, $\mathrm{UV}_{254}$ is reduced at a faster and more consistent rate than DOC as photocatalytic treatment progresses. This contrast in removal efficacy implies that the humic portion of the NOM, which is characterized by higher aromaticity and $\mathrm{UV}_{254}$, is targeted during photocatalysis. This result is in agreement with previous studies (Huang et al., 2008, Liu et al., 2008, Gerrity et al., 2009), which suggests that the complex and heterogeneous composition of NOM is progressively broken into smaller, less aromatic intermediates, whereas complete mineralization (signified by loss of DOC) may only be achieved after extended treatment, or not at all due to the presence and/or production of refractory compounds. Accordingly, although aromaticity decreases, DOC reduction occurs only through physical removal via adsorption (dark adsorption) or as a result of mineralization of the organics to $\mathrm{CO}_{2}$ and $\mathrm{H}_{2} \mathrm{O}$, which is observed in higher energy samples.

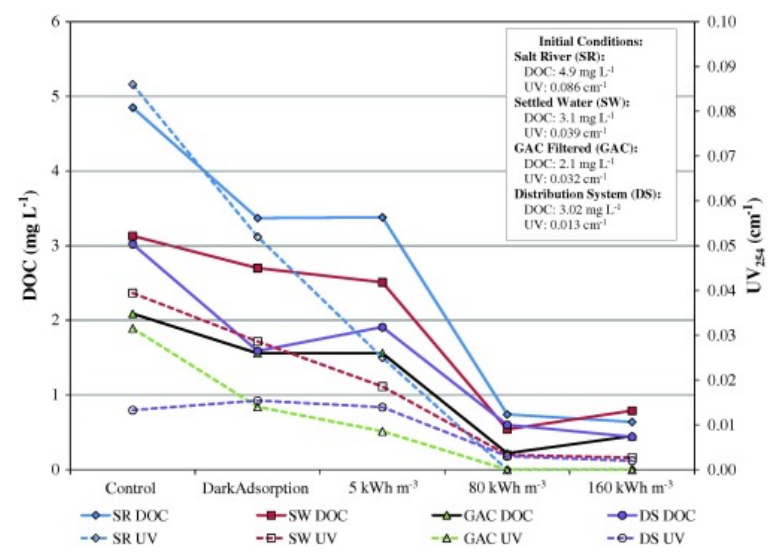

Fig. 1. Removal profile for $D O C$ and $U_{254}$.

The adsorption of organic matter onto the surface of $\mathrm{TiO}_{2}$ is believed to be a function of size and hydrophobicity, with larger and more hydrophobic compounds adsorbing more readily (Huang et al., 2008, Tercero Espinoza and Frimmel, 2009, Philippe et al., 2010a). This supports the relatively large reductions in both DOC and $U_{254}$ generally observed in the dark adsorption samples. This differential adsorption of NOM onto the catalyst surface appears to be responsible for the "preferential photocatalytic degradation" of higher molecular weight fractions rather than specific targeting by radical species (Tercero Espinoza and Frimmel, 2009, Philippe et al., 2010a). Comparing the organic removals for the dark adsorption samples to the limited photocatalysis samples $\left(5 \mathrm{~kW} \mathrm{~h} \mathrm{~m}^{-3}\right)$, DOC levels remain relatively constant while $\mathrm{UV}_{254}$ generally demonstrates additional reduction. Using extended photocatalysis, a substantial fraction of the organic material is mineralized, as evidenced by the reduction of $D O C$ and $U_{254}$. However, while $U_{254}$ is virtually eliminated given sufficient $A O P$ exposure, DOC appears to reach a plateau, indicating the presence of a refractory component that resists photocatalytic oxidation.

As a relative index of humic content and aromaticity, SUVA is commonly used as an indicator of the effectiveness of enhanced coagulation in the reduction of NOM, DOC, and DBP precursors (Edzwald and Tobiason, 1999, Marhaba and Pipada, 2000, Krasner et al., 2006). With increasing photocatalytic treatment, SUVA decreased substantially, and since SUVA affords an accurate predictor of TOC reactivity in terms of DBP formation (Kitis et al., 2001, Krasner et al., 2006), this suggests that fewer DBPs will be produced.

Bromide is an important inorganic DBP precursor, and when present in excess of $100 \mu \mathrm{L} \mathrm{L}^{-1}$, the formation of brominated DBPs may be of concern (Zhang et al., 2011). However, in low bromide waters, such as those typically encountered in central Arizona, chlorinated species tend to dominate (Richardson et al., 1999). In this 
study, the maximum bromide concentration observed was $32 \mu \mathrm{g} \mathrm{L}^{-1}$, which substantially limited the formation of brominated DBPs. As significant reduction of bromide is difficult and results only from the use of sufficiently small-pore-sized membranes (WHO, 2000), photocatalytic treatment minimally impacted bromide levels, as expected.

\subsection{DBPs}

The effect of various DBP mitigation strategies on the formation of TTHMs has been more widely studied in comparison to the formation of HAA5s (Liu et al., 2008, Bond et al., 2009). In this study, TTHMs and HAA5s were evaluated simultaneously, which is valuable as their respective formation potentials may be disproportionately affected by variations in the initial concentration and composition of organic matter. For example, hydrophilic moieties have been reported to be major precursors of HAA5s, while the hydrophobic fraction is more relevant for TTHM formation (Hwang et al., 2001, Liu et al., 2008).

The 24-h formation of TTHMs, HAA5s, and specific DBPs (DBPs normalized to the DOC concentration, $\mu \mathrm{gg}^{-1}$ ) following photocatalytic treatment are shown in Fig. 2. The formation of TTHMs and HAA5s appear to be well correlated, which may be the case for uniform treatment conditions and low bromide water sources (Singer, 1993). While no single species of TTHM appeared dominant, extended photocatalysis consistently reduced bromoform levels. As is commonly the case, di- and trichloroacetic acid were the dominant species of HAA5s, accounting for $50-100 \%$ of all samples (WHO, 2000). The fractions of mono- and dibromoacetic acid were consistently reduced with increasing treatment. A shift toward brominated species is often observed following treatment processes targeting NOM (WHO, 2000), but was not readily apparent here, likely due to low initial concentrations of bromide in the source waters.

(a)

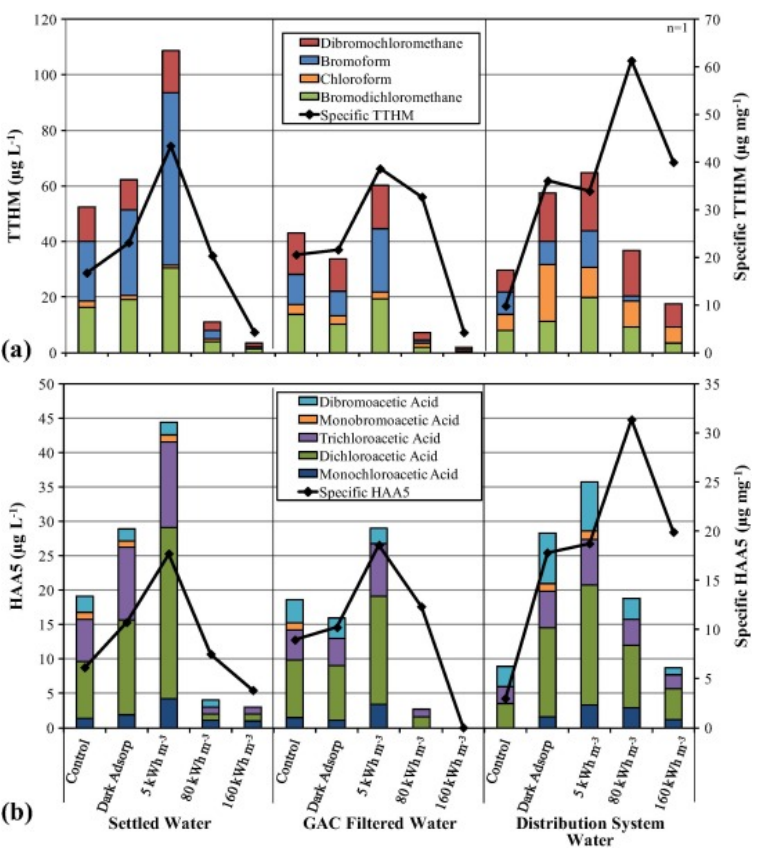

Fig. 2. DBP and specific DBP formation [(a) TTHM and (b) HAA5] as a function of source water and extent of photocatalytic treatment.

Whereas reductions in the DBP precursors DOC, $U V_{254}$, and SUVA were consistently observed following photocatalytic treatment, DBP concentrations generally increased with filtration (dark adsorption) and limited photocatalysis $\left(5 \mathrm{~kW} \mathrm{~h} \mathrm{~m}^{-3}\right)$ prior to decreasing in response to higher energy inputs. This suggests that the incomplete oxidation products resulting from limited photocatalysis more readily form DBPs regardless of the level of water pretreatment. The specific DBP formation data further support this, showing a sharp increase in 
DBP formation compared to DOC concentration under limited photocatalysis conditions. This is significant in that it suggests that traditional bulk indicators of DBP formation potential (such as DOC, UV 254 , and SUVA) may not tell a complete story for AOPs such as photocatalysis, which fundamentally shift NOM composition rather than physically removing it from the system.

\subsection{Organic matter characterization}

\subsubsection{HPSEC}

The effect of photocatalytic treatment on molecular size distribution was measured using HPSEC. Fig. 3 clearly illustrates that as photocatalysis proceeds, the amount of organic material decreases (the magnitude of the peaks decreases) and the character of the NOM also changes, as expressed through horizontal shifts toward smaller AMWs. During photocatalysis, higher molecular weight material is selectively degraded on the basis of differential adsorption onto the $\mathrm{TiO}_{2}$ surface, thereby shifting the NOM profile towards more hydrophilic, lower molecular weight species, which are further degraded as photocatalysis progresses (Liu et al., 2008, Gerrity et al., 2009, Tercero Espinoza et al., 2009, Philippe et al., 2010a, Philippe et al., 2010b). This shift in the character of the organic matter may lead to the expectation of fewer DBPs produced since higher molecular weight species (1-10 kDa) are commonly believed to be responsible for the production of DBPs (Chow et al., 2005). However, studies have reported correlations between the presence of low AMW species and increased TTHM formation (Amy et al., 1992, Li and Zhao, 2006, Liu et al., 2008, Gerrity et al., 2009). Concurrent with shifts in molecular size distribution in this study, the DBP concentrations initially increase with limited photocatalysis prior to decreasing, which indicates that the smaller AMW fractions may be characterized by increased reactivity, a hypothesis that is supported by the trend in specific DBP formation illustrated in Fig. 2.

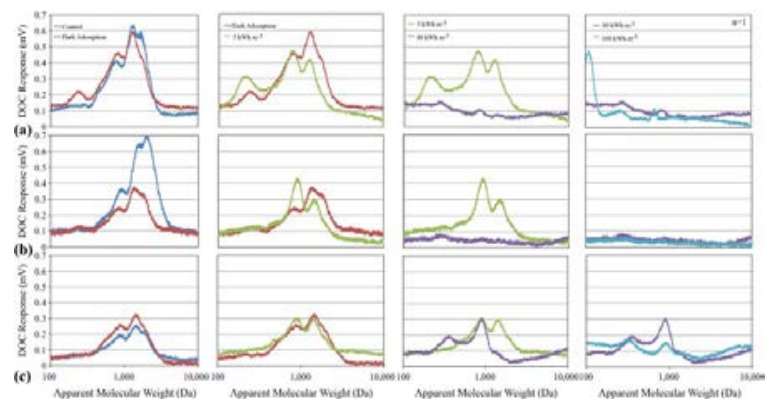

Fig. 3. Size exclusion chromatograms illustrating the progression of mineralization resulting from increasing photocatalytic treatment for (a) settled water, (b) granular activated carbon and (c) distribution system.

The relative distribution of AMW fractions is illustrated in Fig. 4. As a function of increasing treatment, the smallest AMW fraction (0.1-0.5 $\mathrm{kDa}$ ) increases dramatically relative to other size fractions. This is accompanied by substantial relative decreases in the 1-5 kDa range, while the $0.5-1 \mathrm{kDa}$ range remains relatively constant in some waters and decreases in others. Interestingly, the relative fraction of the largest size range included in this study $(5-10 \mathrm{kDa}$ ) increases for all water matrices. One possible explanation for this finding is that a portion of the large molecules is refractory and does not undergo photocatalytic degradation. Thus, as treatment progresses and NOM is mineralized, that refractory component represents a larger percentage of the remaining organic material. 


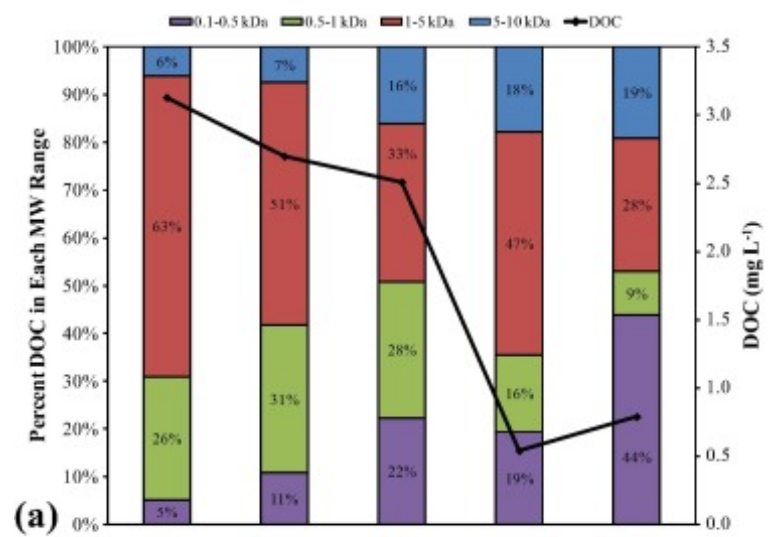

(a)
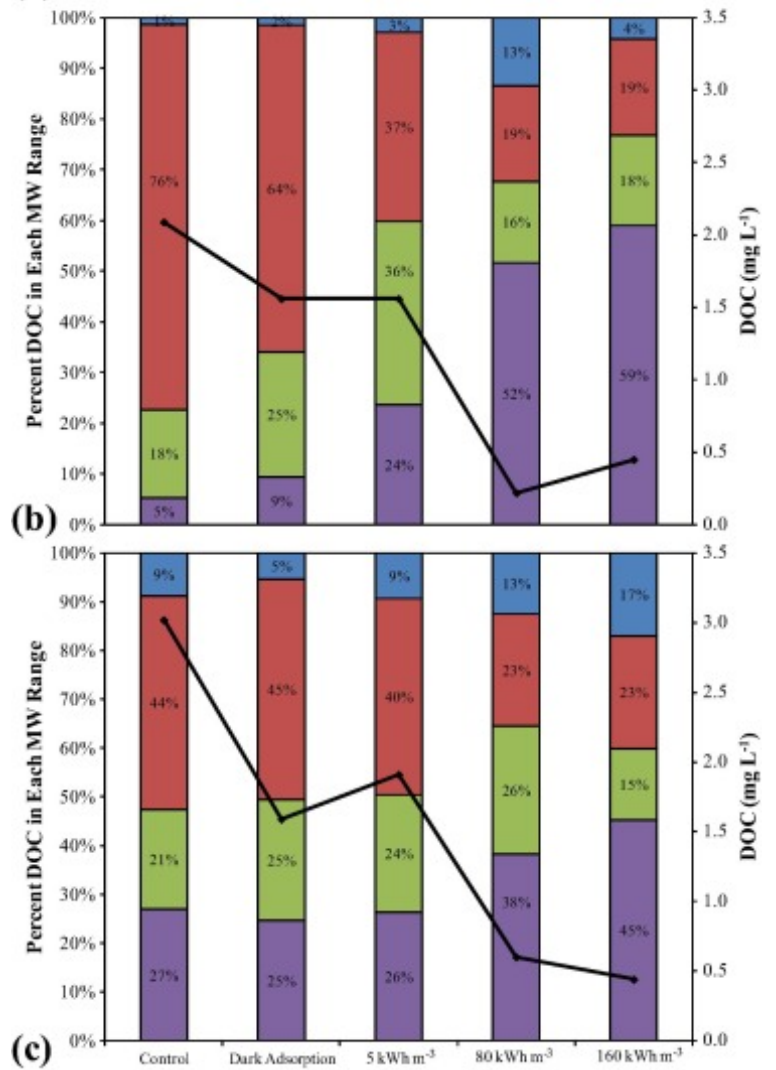

Fig. 4. DOC size distribution resulting from increasing photocatalytic treatment for (a) settled water, (b) granular activated carbon and (c) distribution system.

\subsubsection{EEM}

Qualitative shifts in NOM composition were evaluated using FRI of EEMs, as described by Chen et al. (2003). Fig. 5 summarizes the EEM results. Notably, organic matter shifted away from the humic acid-like fraction (Region V). This is in agreement with the expectation that larger, more hydrophobic organic species (which are characteristic of the largely aromatic humic fraction) more readily adsorb to the surface of the $\mathrm{TiO}_{2}$ particles (Huang et al., 2008, Tercero Espinoza and Frimmel, 2009, Philippe et al., 2010a). Sorption causes "preferential degradation" of these species since they are in close proximity to the highly reactive (short-lived) radical species produced via photocatalysis. However, the shift away from humic materials does not consistently reduce the formation of DBPs, as evidenced by the increases observed for limited photocatalysis. Accordingly, the less aromatic, more hydrophilic fulvic-acid like fraction can also be a significant contributor to DBP production. 


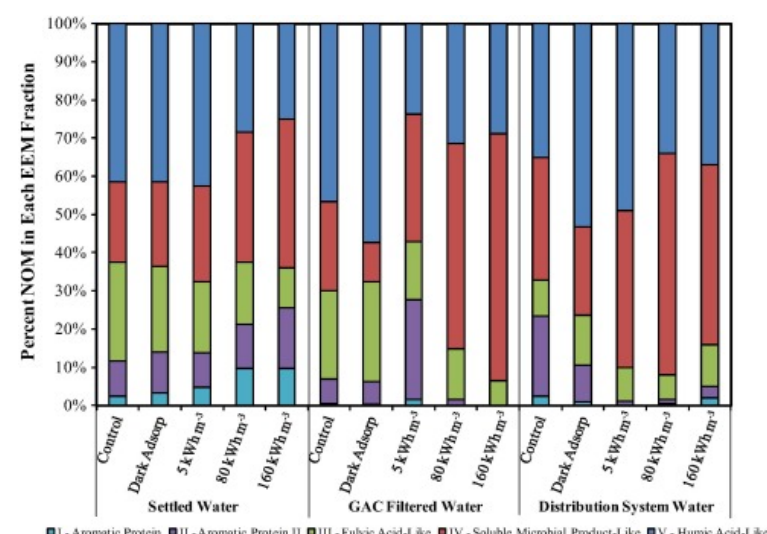

Fig. 5. Relative distribution of fluorescence regional integration of excitation emission matrices as a function of source water and extent of photocatalytic treatment.

\section{Conclusions}

Advanced oxidation processes such as $\mathrm{TiO}_{2}$ photocatalysis are powerful techniques that can be used in a variety of contexts. The use of photocatalysis for targeting DBP reduction is appealing because it is capable of mineralizing organic material. However, if not carefully designed and incorporated as part of a treatment system, $\mathrm{TiO}_{2}$ photocatalysis could potentially exacerbate DBP formation, considerably increase system energy inputs, etc. As shown in this study, when operated under low energy "limited photocatalysis" conditions $\left(5 \mathrm{~kW} \mathrm{~h} \mathrm{~m}^{-3}\right)$, DBP precursors such as $\mathrm{UV}_{254}, \mathrm{DOC}$, and SUVA decrease, but NOM undergoes incomplete oxidation, wherein higher molecular weight, aromatic, humic-like material is adsorbed to the $\mathrm{TiO}_{2}$, and is rearranged by the photo-radicals, but not completely destroyed. This produces organic species which appear to readily react with chlorine and can actually increase the formation of DBPs. This occurs regardless of initial water quality (e.g., settled, GAC filtered, or from the distribution system), suggesting that limited photocatalysis is not an effective means of mitigating DBPs at any point in the treatment train. Alternately, higher energy "extended photocatalysis" (80-160 $\mathrm{kW} \mathrm{h} \mathrm{m}^{-3}$ ) can reduce the formation of TTHMs and HAA5s dramatically, but requires much more energy, likely making it infeasible for high flowrate water treatment operations regardless of source water quality. Accordingly, photocatalysis may be most appropriate for use in targeted applications where high energy consumption per volume of water may be less constrictive, e.g., at a distribution hot spot with relatively low flowrates or in industrial applications targeting particularly recalcitrant contaminants.

\section{Acknowledgements}

This research was supported by the National Science Foundation (NSF) Water \& Environmental Technology Center at Arizona State University and the Arizona Water Institute. All opinions expressed in this paper are the authors' and do not necessarily reflect the policies and views of NSF or Purifics. The authors would like to acknowledge the laboratory assistance and insight provided by Kiril Hristovski, Paul Westerhoff, Chao-An Chin, David Ladner, and Aaron Dotson at Arizona State University. Special thanks are also extended to City of Scottsdale personnel including Susan Butler, Laura McCasland, Kathy Gettens, Carie Wilson, Binga Talabi, and Don Henderson. Finally, we would like to thank Tony Powell of Purifics for his support of the project and use of the Photo-CAT.

\section{References}

Amy et al., 1992. G.L. Amy, R.A. Sierka, J. Bedessem, D. Price, L. Tan. Molecular size distributions of dissolved organic matter. J. Am. Water Work. Assoc., 84 (6) (1992), pp. 67-75 
APHA, 2005. APHA, 2005. Standard Methods for the Examination of Water and Wastewater, 21st Ed. In: Eaton, A.D., Clescen, L.S., Rice, E.W., Greenberg, A.E. (Eds.), American Public Health Association, Washington, DC.

Bond et al., 2009. T. Bond, O. Henriet, E.H. Goslan, S.A. Parsons, B. Jefferson. Disinfection byproduct formation and fractionation behavior of natural organic matter surrogates. Environ. Sci. Technol., 43 (2009), pp. 5982-5989

Chen et al., 2003. W. Chen, P. Westerhoff, J.A. Leenheer, K. Booksh. Fluorescence excitation-emission matrix regional integration to quantify spectra for dissolved organic matter. Environ. Sci. Technol., 37 (2003), pp. 5701-5710

Chow et al., 2005. A.T. Chow, S. Gao, R.A. Dahlgren. Physical and chemical fractionation of dissolved organic matter and trihalomethane precursors: a review. J. Water Supply Res. Technol., 54 (2005), pp. 475-507

Edzwald and Tobiason, 1999. J.K. Edzwald, J.E. Tobiason. Enhanced coagulation: US requirements and a broader view. Water Sci. Technol., 40 (9) (1999), pp. 63-70

Gerrity et al., 2008. D. Gerrity, H. Ryu, J. Crittenden, M. Abbaszadegan. Photocatalytic inactivation of viruses using titanium dioxide nanoparticles and low-pressure UV light. J. Environ. Sci. Health A, 43 (2008), pp. $1261-1270$

Gerrity et al., 2009. D. Gerrity, B. Mayer, H. Ryu, J. Crittenden, M. Abbaszadegan. A comparison of pilot-scale photocatalysis and enhanced coagulation for disinfection byproduct mitigation. Water Res., 43 (2009), pp. 1597-1610

Her et al., 2002. N. Her, G. Amy, D. Foss, J. Cho, Y. Yoon, P. Kosenka. Optimization of method for detecting and characterizing NOM by HPLC-size exclusion chromatography with UV and on-line DOC detection. Environ. Sci. Technol., 36 (2002), pp. 1069-1076

Hua and Reckhow, 2007. G. Hua, D. Reckhow. Comparison of disinfection byproduct formation from chlorine and alternative disinfectants. Water Res., 41 (2007), pp. 1667-1678

Huang et al., 2008. X. Huang, M. Leal, Q. Li. Degradation of natural organic matter by $\mathrm{TiO}_{2}$ photocatalytic oxidation and its effect on fouling of low-pressure membranes. Water Res., 42 (2008), pp. 1142-1150

Hwang et al., 2001. C.J. Hwang, M.J. Sclimenti, A. Bruchet, J.-P. Croue, G.L. Amy. DBP Yields of Polar NOM Fractions from Low Humic Waters. AWWA, Denver CO (2001)

Kitis et al., 2001. M. Kitis, T. Karanfil, J.E. Kilduff, A. Wigton. The reactivity of natural organic matter to disinfection by-products formation and its relation to specific ultraviolet absorbance. Water Sci. Technol., 43 (2) (2001), pp. 9-16

Krasner et al., 2006.

S.W. Krasner, H.S. Weinberg, S.D. Richardson, S.J. Pastor, R. Chinn, M.J. Sclimenti, G.D. Onstad, A.D. Thru ston. Occurrence of a new generation of disinfection byproducts. Environ. Sci. Technol., 40 (2006), pp. 7175-7185

Li and Zhao, 2006. X. Li, H. Zhao. Development of a model for predicting trihalomethanes propagation in water distribution systems. Chemosphere, 62 (2006), pp. 1028-1032

Liu et al., 2008. S. Liu, M. Lim, R. Fabris, C. Chow, M. Drikas, R. Amal. TiO 2 photocatalysis of natural organic matter in surface water: impact on trihalomethane and haloacetic acid formation potential. Environ. Sci. Technol., 42 (2008), pp. 6218-6223

Marhaba and Pipada, 2000. T.F. Marhaba, N.S. Pipada. Coagulation: effectiveness in removing dissolved organic matter fractions. Environ. Eng. Sci., 17 (2000), pp. 107-116

Philippe et al., 2010a. K.K. Philippe, C. Hans, J. MacAdam, B. Jefferson, J. Hart, S.A. Parsons. Photocatalytic oxidation of natural organic matter surrogates and the impact on trihalomethane formation potential. Chemosphere, 81 (2010), pp. 1509-1516

Philippe et al., 2010b. K.K. Philippe, C. Hans, J. MacAdam, B. Jefferson, J. Hart, S.A. Parsons. Photocatalytic oxidation, GAC and biotreatment combinations: an alternative to the coagulation of hydrophilic rich waters? Environ. Technol., 31 (2010), pp. 1423-1434

Richardson, 2003. S. Richardson. Disinfection by-products and other emerging contaminants in drinking water. TrAC Trends Anal. Chem., 22 (2003), pp. 666-684 
Richardson et al., 1999.

S.D. Richardson, A.D. Thruston, T.V. Caughran, P.H. Chen, T.W. Collette, T.L. Floyd, K.M. Schenck, B.W. Ly kins, G. Sun, G. Majetich. Identification of new drinking water disinfection byproducts formed in the presence of bromide. Environ. Sci. Technol., 33 (1999), pp. 3378-3383

Singer, 1993. P.C. Singer. Formation and characterization of DBPs. G.F. Craun (Ed.), Safety of Water Disinfection:

Balancing Chemical and Microbial Risks, ILSI Press, Washington, DC (1993)

Tercero Espinoza and Frimmel, 2009. L.A. Tercero Espinoza, F.H. Frimmel. A simple simulation of the degradation of natural organic matter in homogeneous and heterogeneous advanced oxidation processes. Water Res., 43 (2009), pp. 3902-3909

Tercero Espinoza et al., 2009. L.A. Tercero Espinoza, E. ter Haseborg, M. Weber, F.H. Frimmel. Investigation of the photocatalytic degradation of brown water natural organic matter by size exclusion chromatography. Appl. Catal. B Environ., 87 (2009), pp. 56-62

Thiruvenkatachari et al., 2008. R. Thiruvenkatachari, S. Vigneswaran, I.S. Moon. A review on UV/TiO2 photocatalytic oxidation process. Korean J. Chem. Eng., 25 (2008), pp. 64-72

USEPA, 2006. USEPA, 2006. National Primary Drinking Water Regulations: Stage 2 Disinfectants and Disinfection Byproducts Rule.

WHO, 2000. WHO, 2000. Environmental Health Criteria 216: Disinfectants and Disinfectant By-Products. Geneva. Zhang et al., 2011. J. Zhang, J. Yu, W. An, J. Liu, Y. Wang, Y. Chen, J. Tai, M. Yang. Characterization of disinfection byproduct formation potential in 13 source waters in China. J. Environ. Sci., 23 (2011), pp. 183-188 